\title{
Dietary assessment of older and more educated pregnant women in Ireland during their third trimester
}

\author{
A. Kennedy, S. A. O’Neill and T. Harrington \\ School of Nursing and Human Sciences, Dublin City University, Dublin, Republic of Ireland
}

Optimal nutrition during pregnancy is critical given the potential long term impact that nutritional imbalance has upon the risk of morbidity and mortality for the infant ${ }^{(1-3)}$. High intakes of fat and low intakes of carbohydrates during pregnancy can result in a higher risk of impaired glucose tolerance for the mother ${ }^{(4,5)}$ and a larger-for-gestational-age birth ${ }^{(6)}$. Previous research has shown that older, higher income, more educated pregnant women have a better overall quality of $\operatorname{diet}^{(7,8)}$. However, little research has investigated women's diets during the final trimester of pregnancy, when foetal growth is fastest. The aim of this study was to assess the diets' of a group of women living in Ireland, during the third trimester of pregnancy. Eighty-seven pregnant women were recruited during the third trimester of pregnancy (32-38 weeks gestation). Diets were assessed using a 7-day semi-quantitative food diary and analysed using Dietplan 6.4 and SPSS 17.0.

Results showed the mean age of the women were 35 years. The majority of women taking part in the study were Irish nationals $(81.6 \%)$, married $(83.9 \%)$, employed $(81.6 \%)$ and educated to degree level or higher $(88.5 \%)$. An imbalance in the intake of macronutrients was reported, with majority of women consuming higher than recommended levels of fat (37\%) and saturated fat $(15 \%)$ and lower than recommended levels of carbohydrates (49\%) as a proportion of their energy intakes.

\begin{tabular}{llll}
\hline Nutrient & Group Mean & Irish Recommendations & $\%$ above Recommendations \\
\hline Protein & $15 \%$ & $10-15 \%$ & $31 \%$ \\
Carbohydrate & $49 \%$ & $55 \%$ & $14 \%$ \\
Fat & $37 \%$ & $30-35 \%$ & $69 \%$ \\
Saturated Fat & $15 \%$ & $<10 \%$ & $92 \%$ \\
\hline
\end{tabular}

While the estimated micronutrient intakes were above the Recommended Dietary Allowances (RDA-including an increment for pregnancy) ${ }^{(9)}$ for the majority of nutrients investigated, some important nutrients had mean intakes below the RDA.

\begin{tabular}{lccrl}
\hline Nutrient & Group Mean & $S D$ & RDA & \% below Recommendations RDA \\
\hline Calcium $(\mathrm{mg} / \mathrm{d})$ & 1023 & 263 & 1200 & $74 \%$ \\
Iron $(\mathrm{mg} / \mathrm{d})$ & 12.5 & 3.5 & 15 & $82 \%$ \\
Vitamin D $(\mu \mathrm{g} / \mathrm{d})$ & 2.79 & 1.64 & 10 & $100 \%$ \\
Folate $(\mu \mathrm{g} / \mathrm{d})$ & 278.3 & 88.2 & 500 & $99 \%$ \\
\hline
\end{tabular}

This data suggests that despite being from a more advantaged and more educated background, pregnant women are consuming high intakes of fat and saturated fat in their diet and are not reaching the recommended intakes of essential vitamins and minerals during their third trimester of pregnancy. The high level of fat in the diet indicates a lack of awareness regarding the importance of nutrient dense foods during pregnancy to meet increased micronutrient requirements. It also highlights the need for further and more targeted education and interventions among pregnant women to achieve the current dietary guidelines.

1. McDonald SD, Han Z, Mulla S et al. (2010) BMJ: British Medical Journal 341.

2. Olson CM, Strawderman MS, Dennison BA (2009) Matern Child Health J 13(6): 839-846.

3. Godfrey KM \& Barker DJP (2001) Public Health Nutr 4(2b): 611-624.

4. Moses RG, Shand JL, Tapsell LC (1997) Diabetes Care 20(11): 1647.

5. Saldana TM, Siega-Riz AM, Adair LS (2004) Am J Clin Nutr 79(3): 479.

6. Scholl TO, Chen X, Khoo CS et al. (2004) Am J Epidemiol 159(5): 467.

7. Murrin C, Fallon UB, Hannon F et al. (2007) Ir Med J 100(Suppl): S12-S15.

8. Bodnar LM \& Siega-Riz AM (2002) Public Health Nutr 5(06): 801-809.

9. Food Safety Authority of Ireland (1999) Dublin: FSAI. 